\title{
Changes in microstructure and stiffness of Scots pine (Pinus sylvestris L) sapwood degraded by Gloeophyllum trabeum and Trametes versicolor - Part II: Anisotropic stiffness properties
}

\author{
Thomas K. Bader ${ }^{1} *$, Karin Hofstetter ${ }^{1}$, \\ Gry Alfredsen ${ }^{2}$ and Susanne Bollmus ${ }^{3}$ \\ ${ }^{1}$ Institute for Mechanics of Materials and Structures, \\ Faculty for Civil Engineering, Vienna University of \\ Technology, A-1040 Vienna, Austria \\ ${ }^{2}$ Norwegian Forest and Landscape Institute, NO-1431 Ås, \\ Norway \\ ${ }^{3}$ Georg-August-University of Göttingen, Wood Biology \\ and Wood Products, D-37077 Göttingen, Germany \\ * Corresponding author. \\ Institute for Mechanics of Materials and Structures, \\ Faculty for Civil Engineering, \\ Vienna University of Technology, Vienna, Austria \\ E-mail: thomas.bader@tuwien.ac.at
}

\begin{abstract}
Fungal decay considerably affects the macroscopic mechanical properties of wood as a result of modifications and degradations in its microscopic structure. While effects on mechanical properties related to the stem direction are fairly well understood, effects on radial and tangential directions (transverse properties) are less well investigated. In the present study, changes of longitudinal elastic moduli and stiffness data in all anatomical directions of Scots pine (Pinus sylvestris) sapwood which was degraded by Gloeophyllum trabeum (brown rot) and Trametes versicolor (white rot) for up to 28 weeks have been investigated. Transverse properties were found to be much more deteriorated than the longitudinal ones. This is because of the degradation of the polymer matrix between the cellulose microfibrils, which has a strong effect on transverse stiffness. Longitudinal stiffness, on the other hand, is mainly governed by cellulose microfibrils, which are more stable agains fungal decay. G. trabeum (more active in earlywood) strongly weakens radial stiffness, whereas T. versicolor (more active in latewood) strongly reduces tangential stiffness. The data in terms of radial and tangential stiffnesses, as well as the corresponding anisotropy ratios, seem to be suitable as durability indicators of wood and even allow conclusions to be made on the degradation mechanisms of fungi.
\end{abstract}

Keywords: biodegradation; brown rot; chemical and physical properties; micromechanics; Scots pine; softwood; white rot.

\section{Introduction}

Wood is highly anisotropic, as demonstrated by macroscopic mechanical tests. This is because of the sophisticated morphology of the wood tissue and the hierarchically wellorganized supramolecular architecture of the cell wall at the micro- and nano-level (Salmén and Burgert 2009; Stevanic and Salmén 2009). Fungal deterioration alters the nano- and microstructure (Côté 1965; Fengel and Wegener 1984; Schwarze 2007) and results in corresponding changes in mechanical properties (Wilcox 1978; Winandy et al. 2000; Curling et al. 2001, 2002).

In short, wood can be considered at four organization levels: (1a) there are cellulose microfibrils (MF) and larger cellulose aggregates with crystalline and non-crystalline (paracristalline) regions and (1b) these are surrounded by an amorphous polymer matrix composed of lignin, hemicelluloses, and extractives, which are, under moist conditions, closely associated with water; (2) at a higher level, the cell wall material is a polymer composite with cellulose in the centre (1a) embedded in the amorphous matrix (1b); in the thickest layer of the cell wall (the S2 layer), the MFs are highly oriented and their inclination to the cell axis is described by the microfibril angle (MFA); (3) at the macroscopically well-visible level, the cellular honeycomb structure of cells dominate the image, which is subsequently formed over a growth period [from earlywood (EW) to latewood (LW)] with a continuous decrease in radial dimensions of the cells, accompanied by an increase in cell wall thickness. This results in the typical (4) growth ring structure, which is, in the case of softwoods, always visible to the naked eye (Kollmann and Côté 1968).

The degradation and modification of wood constituents at the nano- and micro-level by fungal decay entails the loss of strength properties at the macroscopic level. The loss depends on fungal and wood species and growth conditions within the wood (Fengel and Wegener 1984). Traditionally, the fungal effect on wood is measured by the mass loss (ML; Hartley 1958 in Wilcox 1978). In cases of initial fungal decay, if ML is still not observable, strength and stiffness may already have decreased (Curling et al. 2001, 2002; Brischke et al. 2008; Humar et al. 2008). This reveals the dominant influence of microstructural changes on the overall material behavior.

The relationship between the microstructural and mechanical effects of fungal decay were investigated by Winandy et al. (2000) and Curling et al. (2001, 2002). The quoted authors measured stiffness and strength properties in bending 
tests on Southern pine samples, which were degraded by Gloeophyllum trabeum and Postia placenta (both brown rots), respectively, for up to 12 weeks; the changes in chemical composition were also observed. These experiments indicated that hemicelluloses are degraded from the very beginning, before the glucan content (as a result of cellulose decay) decreased. At about 30\% ML, the samples lost their structural integrity. At this point, the glucan content, and also the modulus of elasticity (MOE) in bending tests, start to decrease rapidly. Accordingly, the MOE in the longitudinal direction is strongly related to cellulose content. Similar results were found by Humar et al. (2008) by means of Fourier transform-infrared (FT-IR) spectroscopy in combination with dynamic mechanical testing on Norway spruce and Scots pine degraded by Antrodia vaillantii and G. trabeum (both brown rots).

All reported investigations focused exclusively on the effects of fungal decay in terms of the mechanical properties in the longitudinal direction. On the other hand, the mechanical properties in the transverse directions (radial and tangential) are expected to be much more sensitive to degradation. This is at least known from thermally modified wood, as described by Korkut (2008), and from immediate effects of high temperatures on the mechanical behavior of wood, as described by Gerhards (1982). Recently, it was shown by Przewloka et al. (2008) that radial stiffness and the radial compressive strength of water-saturated wood samples may constitute suitable indicators to detect incipient decay.

This was the motivation for the present work. The effects of fungal degradation on anisotropic stiffness properties should be investigated also considering changes in physical and chemical characteristics. In particular, Scots pine (Pinus sylvestris) sapwood degraded by G. trabeum (brown rot) and by Trametes versicolor (white rot), respectively, were in focus. The methods applied were tensile testing and ultrasonic testing for the purpose of quantifying the elastic anisotropic stiffness properties of the specimens in initial and advanced states of degradation. Ultrasonic testing has a long tradition in wood mechanics and was not only used for measuring the stiffness properties of clear wood (Bucur 2006), but also for decayed wood (Ross and Pellerin 1994).

The experimental results presented herein are set in relation to changes in the physical and chemical properties of the same samples presented in the first part of this contribution (Bader et al. 2012). Consequently, conclusions on microstructure/stiffness-relationships can be drawn. In particular, the goal was to answer the question of whether transverse or longitudinal stiffnesses are more sensitive to degradation. Moreover, it should be contributed to the knowledge about the relationship between the chemical composition and changes in the mechanical properties. The expectation was that stiffness properties could be useful as durability indicators against fungi.

\section{Material and methods}

Four hundred and six specimens of Scots pine (P. sylvestris L.) sapwood with dimensions of $20 \times 15 \times 130 \mathrm{~mm}^{3}(\mathrm{R} \times \mathrm{T} \times \mathrm{L})$ were characterized in the initial condition. To this purpose, the longitudinal elastic modulus $\left(E_{L}\right)$ of each bar was measured in a tension test and its longitudinal stiffness $\left(C_{L}\right)$ by means of an ultrasonic (US) method.

Out of the 406 specimens, 14 samples served as reference. They were cut into three cuboids with dimensions of $20 \times 15 \times 20 \mathrm{~mm}^{3}$ $(\mathrm{R} \times \mathrm{T} \times \mathrm{L})$ and tested for stiffness in all three principal material directions by US. The remaining samples were exposed to G. trabeum [(Pers.) Murrill, strain CTB 863A] and to T. versicolor [(L.) Lloyd, strain FPRL 280] for up to 28 weeks, 196 bars for each fungus, following the procedure specified in EN 113 (1996). After every second week, 14 specimens were taken out as representatives of one degradation stage. Additionally, 14 beech samples were taken for virulence tests of T. versicolor (EN 113 1996), defined as ML after 16 weeks degradation time. G. trabeum degradation leads to an irregular shape of the specimens. To be able to determine mass density and mean stresses in tensile tests, the samples were reshaped (see Bader et al. 2012). G. trabeum-degraded samples were only tested up to 16 weeks degradation, as for longer degradation stages the specimens were considerably cracked and tended to crumble apart. T. versicolor-degraded samples, however, could be mechanically characterized for up to 28 weeks degradation time.

After tensile testing of the degraded samples, three cuboids with corresponding cross-sections and $20 \mathrm{~mm}$ length $\left(l_{L}\right)$ were cut out of each bar and used for US testing. All mechanical tests were performed under constant climatic conditions of $20^{\circ} \mathrm{C}$ and $65 \%$ relative humidity (RH).

Physical and chemical properties of the samples in initial and degraded states were measured (Bader et al. 2012) for the entire test program.

\section{Tensile tests}

Tensile tests were performed on a MTS 858 MiniBionix (MTS Systems corporation, Eden Prairie, MN, USA) with a $15 \mathrm{kN}$ load cell. Longitudinal strain was measured by $H B M D D 1$ clamp-on strain transducers (Hottinger Baldwin Messtechnik GmbH, Wien, Austria) with a zero span of $25 \mathrm{~mm}$ (Figure 1a). To ensure elastic conditions during the measurement, tensile specimens were loaded with a cross head speed of $0.3 \mathrm{~mm} \mathrm{~min} \mathrm{~m}^{-1}$ up to a maximum displacement of $0.3 \mathrm{~mm}$, which resulted in a maximum stress between 5 and $10 \mathrm{MPa}$ depending on the stiffness of the specimens in the initial and degraded states, respectively. The $E_{L}$ was calculated by fitting regression to the linear part of the recorded curve $(10-80 \%$ of maximum applied stress).

\section{Ultrasonic tests}

US tests were performed by means of a pulser-receiver $P R 5077$ (Panametrics Inc., Waltham, MA, USA), a digital oscilloscope (WaveRunner 62Xi, Lecroy Corp., Chestnut Ridge, NY, USA), a pair of US transducers for longitudinal pulses with a frequency of $100 \mathrm{kHz}$ (Panametrics Inc.), honey as coupling medium and an auxiliary testing device to hold the transducers (Figure 1b). In addition, a delay line cylinder made of aluminum alloy 5083 with a height of $20 \mathrm{~mm}$, referring to a time delay of $3.77 \mu \mathrm{s}$, was used to relocate the receiver signal out of the time range of receiver disturbances (Figure 1b). A cellophane film was used to prevent the coupling medium honey from infiltrating the wood microstructure. All tests were performed in transmission-through mode in the L, R, and $\mathrm{T}$ direction. The oscilloscope yields the time of flight of the ultrasonic wave through the specimen $t_{i}$, which provides, in combination with the travel distance through the specimen, $l_{i}$, the phase velocity in a specific material direction $i=L, R, T$ of the wave as 

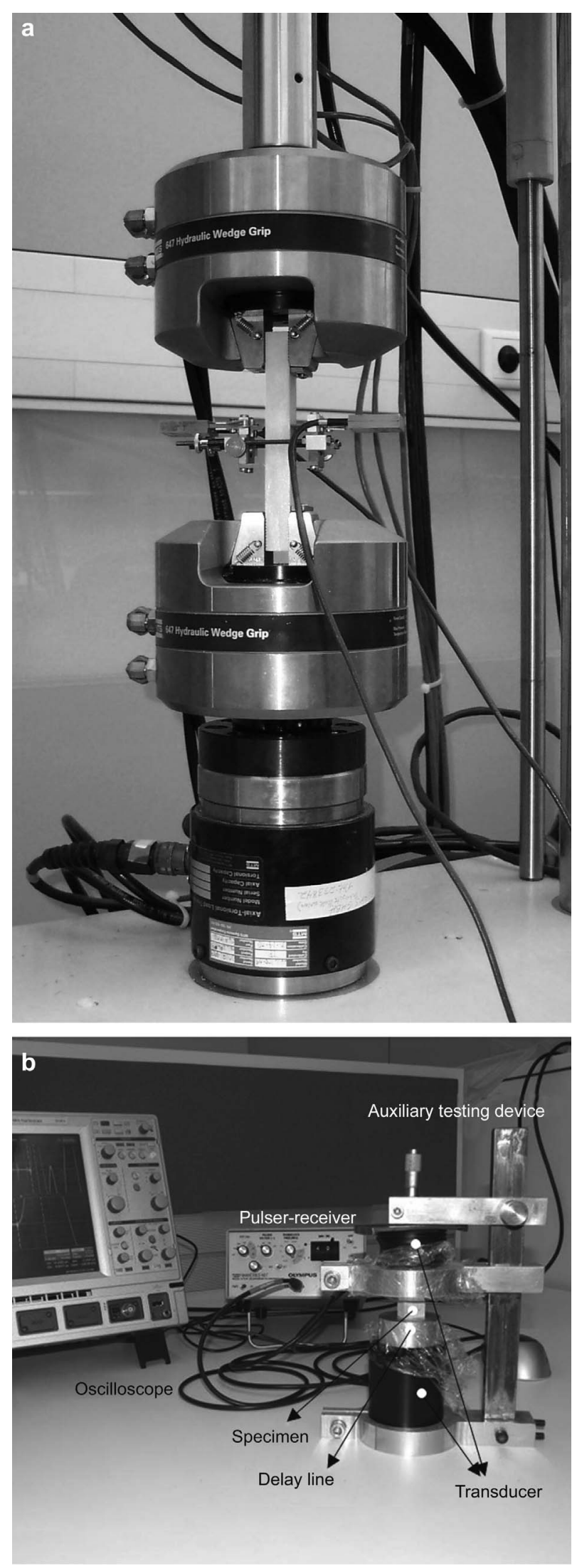

Figure 1 Experimental set-up for (a) tensile tests and (b) ultrasonic tests. $v_{i}=l_{i} / t_{i}$. Elastic stiffnesses, or more precisely elasticity tensor components $C_{i}$, related to the corresponding direction are then obtained from:

$C_{i}=\rho \cdot v_{i}^{2}$,

where sample-specific mass densities $(\rho)$ were employed. Anisotropic stiffnesses of wood are a function of three independent elastic moduli $E_{i}$ and three independent Poisson ratios $v_{i j}$. Thus, it is not possible to directly derive the $E_{L}$ in one material direction from the corresponding stiffnesses.

\section{Results and discussion}

\section{Mechanical properties under initial conditions}

The mass densities $(\rho)$ of the samples under ambient conditions of $20^{\circ} \mathrm{C}$ and $65 \% \mathrm{RH}$ varied between 0.474 and $0.622 \mathrm{~g} \mathrm{~cm}^{-3}$. Mechanical tests revealed longitudinal $E_{L}$ between 8.56 and $20.42 \mathrm{GPa}$. The average was $14.41 \mathrm{GPa}$ ( $\pm 2.34 \mathrm{GPa}, n=406)$, where the values in parentheses refer to corresponding standard deviations, followed by the number of test specimens, $n$. The longitudinal stiffness $C_{L}$ was between 11.17 and $22.03 \mathrm{GPa}$ with an average of $18.26 \mathrm{GPa}$ $\left( \pm 1.88 \mathrm{GPa}, n=406\right.$; Figure 2 ). As expected, $C_{L}$ values are higher than corresponding elastic moduli (Bucur 2006). In an exemplary manner, the considerable influence of the microstructure on the properties $E_{L}$ and $C_{L}$ is pointed out by means of the effect of $\rho$, expressed in the following relationships:

$$
\begin{aligned}
& E_{L}(\rho)=56.76 \rho-16.91[\mathrm{GPa}]\left(R^{2}=0.48\right), \\
& C_{L}(\rho)=47.36 \rho-7.92[\mathrm{GPa}]\left(R^{2}=0.52\right) .
\end{aligned}
$$

These relationships are obtained by a linear fit to the results shown in Figure 2, with the specified coefficients of determination $R^{2}$ agreeing well with the data of previous reports (Eberhardsteiner 2002).

The transverse elastic behavior of the samples under the initial condition in $\mathrm{R}$ and $\mathrm{T}$ directions was investigated by

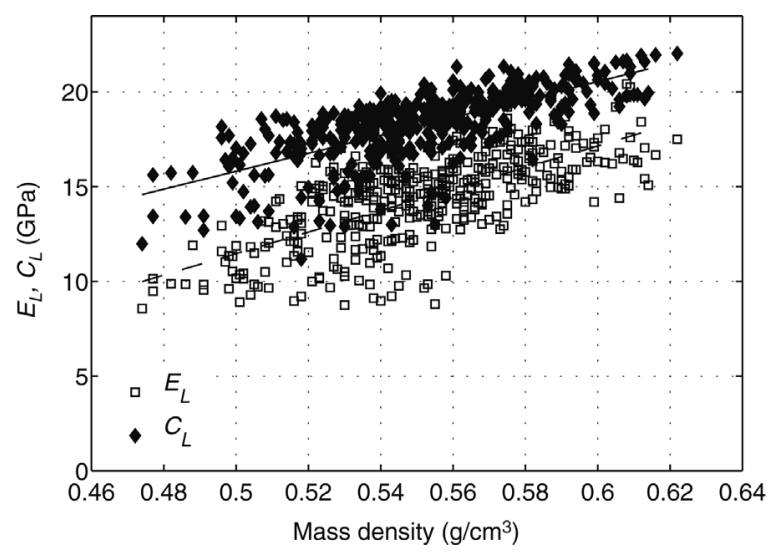

Figure 2 Initial stiffness properties of samples under initial conditions, namely longitudinal elastic modulus in tension $E_{L}$ and longitudinal stiffness $C_{L}$ as function of density. 
means of 42 reference cuboids cut out of the 14 reference specimens. $C_{R}$ and $C_{T}$ were found to be between 2.27 and $2.95 \mathrm{GPa}$ (average $2.67 \mathrm{GPa}, \pm 0.18 \mathrm{GPa}, n=42$ ) and between 1.72 and $2.24 \mathrm{GPa}$ (average $1.95 \mathrm{GPa}, \pm 0.20 \mathrm{GPa}$, $n=42$ ), respectively. Corresponding anisotropy ratios amounted to $1.38( \pm 0.13), 7.18( \pm 0.44)$ and $9.88( \pm 0.86)$ for radial to tangential $\left(C_{R} / C_{T}\right)$, longitudinal to radial $\left(C_{L} / C_{R}\right)$, and longitudinal to tangential $\left(C_{L} / C_{T}\right)$ stiffnesses, respectively. From a micromechanical point of view, these ratios depend on intrinsic characteristics of the wooden microstructure (Keunecke et al. 2007), such as mass density $(\rho)$, MFA, and chemical composition. Thus, changes in the microstructure are reflected in these anisotropy ratios.

\section{Mechanical properties of degraded samples}

Expectedly, both fungi (G. trabeum and T. versicolor) considerably influenced the mechanical properties of Scots pine sapwood. The virulence of the fungi was confirmed and met the requirements of the standards (Bader et al. 2012).

In the course of degradation by $G$. trabeum, all stiffness properties continuously decreased. $E_{L}$ and $C_{L}$ decreased by $41.3 \%( \pm 14.7 \%)$ and $29.8 \%( \pm 10.2 \%)$, respectively, after 16 weeks degradation (Table 1 and Figure 3). The ratio of $C_{L}$ to $E_{L}$ was found to increase considerably from 1.28 $( \pm 0.14)$ to $1.77( \pm 0.40)$ during the same time (Figure 4a). In the case of $E_{L}$ measured in uniaxial tension, the specimen is unconstrained in the transverse directions. US determined stiffness $C_{L}$, on the other hand, relates to the same loading direction, but is obtained under constrained conditions in the

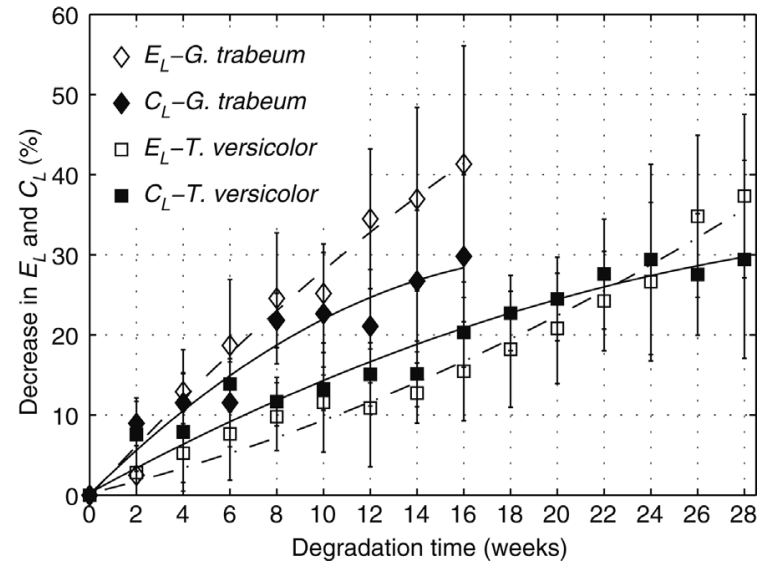

Figure 3 Decrease of longitudinal elastic modulus $E_{L}$ and longitudinal stiffness $C_{L}$ over degradation time by $G$. trabeum and T. versicolor, respectively. Error bars indicate corresponding standard deviations ( $n=14$ for each degradation stage and fungus).

transverse directions. Their relationship is given by (see e.g., Equations 6.3 and 6.4 in Itskov and Aksel 2002):

$C_{L}=E_{L} \frac{1-v_{R T} v_{T R}}{1-v_{R T} v_{T R}-v_{L T} v_{T L}-v_{L R} v_{R L}-2 v_{T R} v_{L T} v_{R L}}$,

where Poisson's ratios $v_{i j}(i \neq j$ and $i, j=L, R, T)$ indicate that the ratio stiffness to elastic modulus depends on the spatial contractions. Consequently, an increase in this ratio relates

Table 1 Relative decrease of longitudinal elastic modulus in tension and of stiffness in longitudinal, radial and tangential direction found in US testing, for Scots pine sapwood degradation by G. trabeum and T. versicolor, for 2-28 weeks.

\begin{tabular}{|c|c|c|c|c|c|c|c|c|c|}
\hline & \multirow[b]{2}{*}{$\begin{array}{l}\text { Weeks } \\
\text { of exp. }\end{array}$} & \multicolumn{2}{|c|}{$E_{L}($ tension $)$} & \multicolumn{2}{|c|}{$C_{L}(\mathrm{US})$} & \multicolumn{2}{|c|}{$C_{R}(\mathrm{US})$} & \multicolumn{2}{|c|}{$C_{T}(\mathrm{US})$} \\
\hline & & $\begin{array}{c}\text { Mean } \\
(\%)\end{array}$ & $\begin{array}{c}\text { Std. dev. } \\
(\%)\end{array}$ & $\begin{array}{c}\text { Mean } \\
(\%)\end{array}$ & $\begin{array}{c}\text { Std. dev. } \\
(\%)\end{array}$ & $\begin{array}{c}\text { Mean } \\
(\%)\end{array}$ & $\begin{array}{c}\text { Std. dev. } \\
(\%)\end{array}$ & $\begin{array}{c}\text { Mean } \\
(\%)\end{array}$ & $\begin{array}{c}\text { Std. dev. } \\
(\%)\end{array}$ \\
\hline \multirow[t]{8}{*}{ G. trabeum (brown rot) } & 2 & 2.5 & 5.0 & 9.0 & 2.8 & 3.2 & 5.6 & -3.1 & 7.7 \\
\hline & 4 & 12.9 & 5.3 & 11.5 & 3.7 & 18.3 & 11.7 & 1.4 & 8.6 \\
\hline & 6 & 18.7 & 8.2 & 11.5 & 5.5 & 33.0 & 15.2 & 10.5 & 9.2 \\
\hline & 8 & 24.6 & 8.2 & 21.8 & 3.4 & 40.2 & 6.9 & 23.1 & 10.2 \\
\hline & 10 & 25.2 & 6.2 & 22.6 & 7.6 & 46.4 & 12.3 & 25.3 & 9.5 \\
\hline & 12 & 34.5 & 8.7 & 21.1 & 7.1 & 60.0 & 16.3 & 22.5 & 17.4 \\
\hline & 14 & 36.9 & 11.4 & 26.7 & 8.8 & 71.3 & 13.9 & 30.9 & 13.5 \\
\hline & 16 & 41.3 & 14.7 & 29.8 & 10.2 & 70.0 & 13.7 & 38.6 & 12.7 \\
\hline \multirow[t]{14}{*}{ T. versicolor (white rot) } & 2 & 2.8 & 5.5 & 7.6 & 4.6 & 2.7 & 8.3 & -2.0 & 8.5 \\
\hline & 4 & 5.2 & 3.7 & 7.9 & 7.4 & 15.0 & 5.0 & 14.5 & 10.1 \\
\hline & 6 & 7.7 & 5.8 & 13.9 & 2.8 & 16.3 & 6.7 & 13.7 & 9.4 \\
\hline & 8 & 9.8 & 4.2 & 11.7 & 3.0 & 11.0 & 8.8 & 15.1 & 11.0 \\
\hline & 10 & 11.6 & 6.2 & 13.3 & 2.7 & 16.1 & 7.0 & 19.7 & 7.5 \\
\hline & 12 & 10.9 & 7.4 & 15.1 & 4.0 & 17.7 & 10.0 & 27.2 & 6.8 \\
\hline & 14 & 12.7 & 3.8 & 15.1 & 4.1 & 24.3 & 6.9 & 29.6 & 7.3 \\
\hline & 16 & 15.5 & 6.2 & 20.3 & 4.4 & 25.5 & 6.7 & 34.3 & 11.3 \\
\hline & 18 & 18.2 & 7.2 & 22.7 & 4.7 & 27.7 & 7.8 & 36.1 & 7.3 \\
\hline & 20 & 20.8 & 6.9 & 24.5 & 5.2 & 26.0 & 7.6 & 39.1 & 10.9 \\
\hline & 22 & 24.2 & 6.2 & 27.6 & 6.8 & 29.0 & 8.5 & 40.5 & 9.8 \\
\hline & 24 & 26.7 & 9.9 & 29.4 & 11.9 & 35.7 & 8.8 & 49.2 & 11.1 \\
\hline & 26 & 34.8 & 10.1 & 27.5 & 7.6 & 36.6 & 9.0 & 53.8 & 11.9 \\
\hline & 28 & 37.3 & 10.2 & 29.4 & 12.4 & 38.8 & 8.4 & 52.7 & 10.9 \\
\hline
\end{tabular}



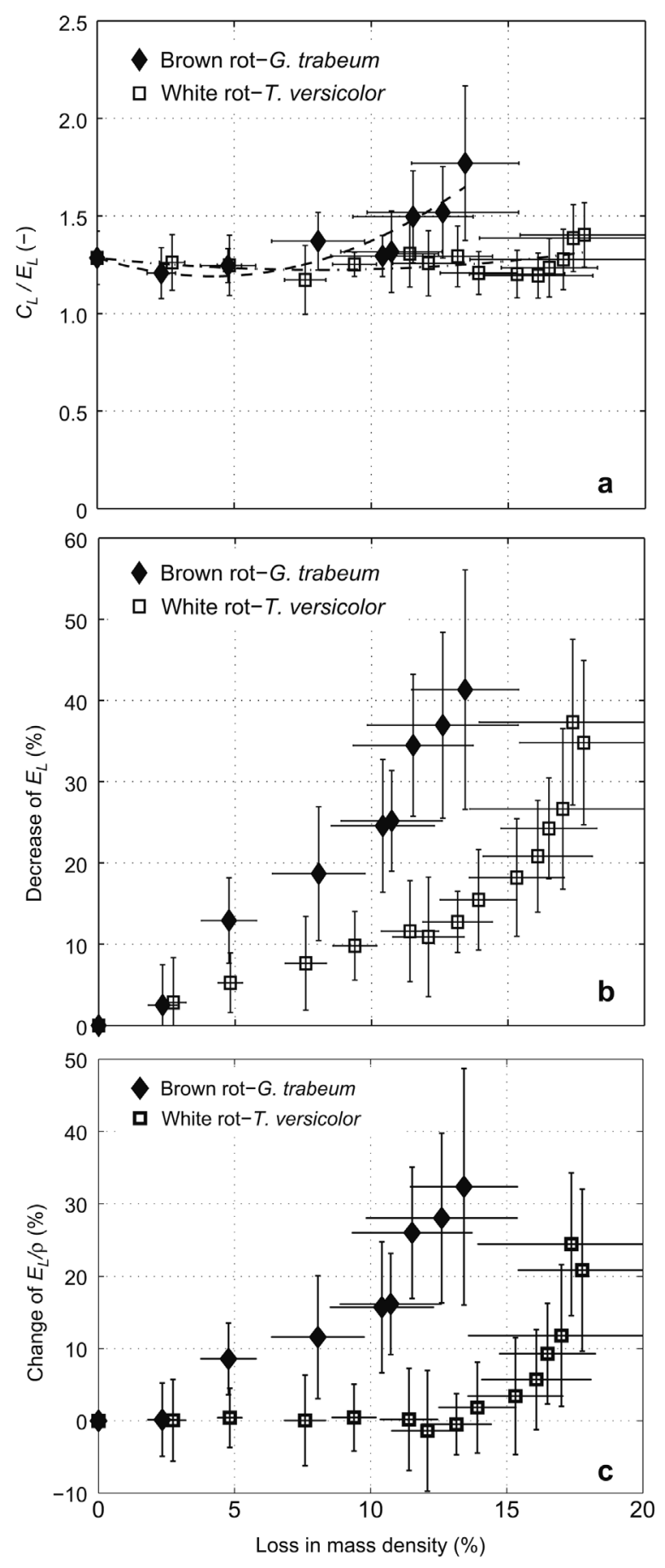

Figure 4 (a) Ratio of longitudinal stiffness $C_{L}$ to longitudinal elastic modulus $E_{L}$. (b) Decrease of the longitudinal elastic modulus $E_{L}$. (c) Change of the cell wall stiffness, expressed by the ratio longitudinal elastic modulus $E_{L}$ plotted over the loss in mass density for degradation by G. trabeum and T. versicolor, respectively. Error bars indicate corresponding standard deviations $(n=14$ for each degradation stage and fungus).

to a higher transverse contraction and, thus, to a lower resistance in the lateral direction. Thus, the increase of the ratio stiffness to elastic modulus observed in our experiments indicates a reduced resistance to lateral contraction upon deg- radation, which is more pronounced than the direct reduction of $C_{L}$.

After 10 weeks of degradation by $G$. trabeum, samples could no longer bear the gripping pressure applied in tensile tests. Therefore, the edges of the samples were strengthened with a resin (SIKA Biresin G27, Sika Österreich $\mathrm{GmbH}$, Bludenz-Bings, Austria). By cutting the samples after testing, visual inspection verified that the resin did not penetrate the testing track of the sample and was therefore not influencing stiffness properties. Similar trends for the changes in stiffness were observed for samples degraded by T. versicolor; however, they were reduced in intensity and were without the aforementioned problems with clamping. $E_{L}$ and $C_{L}$ decreased by $37.3 \%( \pm 10.2 \%)$ and $29.4 \%( \pm 12.4 \%)$, respectively, after 28 weeks degradation time (see Table 1 and Figure 3). The corresponding ratio $C_{L} / E_{L}$ was found to slightly increase from $1.28( \pm 0.14)$ to $1.39( \pm 0.17)$ over the same time, revealing a lower reduction of resistance to lateral contraction than for $G$. trabeum degraded samples (Figure 4a).

Change of mass density $(\rho)$ and decrease of $E_{L}$ show a linear relation over a period of up to 14 weeks of T. versicolor degradation (Figure 4b). This indicates more or less uniform degradation of the cell wall material without affecting its overall chemical composition. This is also expressed by the almost constant density-related stiffness, which is an indicator of the stiffness of the cell wall material, during the first weeks (Figure 4c). Selective degradation of particular polymers within the walls only starts to be dominant after approximately 14 weeks of degradation time. In addition, density-related stiffness is more strongly reduced by G. trabeum than by T. versicolor, as is obvious in Figure 4c.

Compared with the longitudinal properties, transverse stiffness is much more strongly affected by fungal decay, with decreases of up to $70.0 \%( \pm 13.7 \%)$ and $38.6 \%$ $( \pm 12.7 \%)$ for $C_{R}$ and $C_{T}$, respectively, after 16 weeks of degradation by $G$. trabeum (Table 1). Correspondingly, a continuous decrease in the anisotropy ratio of $C_{R} / C_{T}$ from $1.38( \pm 0.13)$ to $0.69( \pm 0.35)$ was found for $G$. trabeum, which is shown in Figure 5a over the corresponding loss in $\rho$. The relationship of $C_{L} / C_{T}$ hardly changed from 9.88 $( \pm 0.86)$ to 10.33 ( \pm 1.89 ) for this fungus. However, the ratio $C_{L} / C_{R}$ increased considerably from $7.18( \pm 0.44)$ to 18.23 ( \pm 8.36 ), as shown in Figure 5b,c, again over the corresponding changes in $\rho$. The two latter anisotropy ratios indicate that transverse stiffness properties are more strongly affected than longitudinal ones, and, particularly, that the radial direction is finally most strongly weakened.

Similar trends were observed for T. versicolor, where, again, transverse stiffness was more strongly reduced than the longitudinal one. Decreases amounted up to $38.8 \%$ $( \pm 8.4 \%)$ and $52.7 \%( \pm 10.9 \%)$ for $C_{R}$ and $C_{T}$, respectively, after 28 weeks (Table 1). Correspondingly, a continuous increase in the anisotropy ratio of $C_{R} / C_{T}$ from $1.38( \pm 0.13)$ to $1.82( \pm 0.28)$ was found (Figure $5 \mathrm{a})$. The ratio of $C_{L} / C_{R}$ only slightly increased from $7.18( \pm 0.44)$ to $7.74( \pm 1.43)$, while a considerable increase from $9.88( \pm 0.86)$ to 13.77 $( \pm 1.71)$ was observed for the ratio of $C_{L} / C_{T}$ (Figure $5 \mathrm{~b}, \mathrm{c}$ ). 

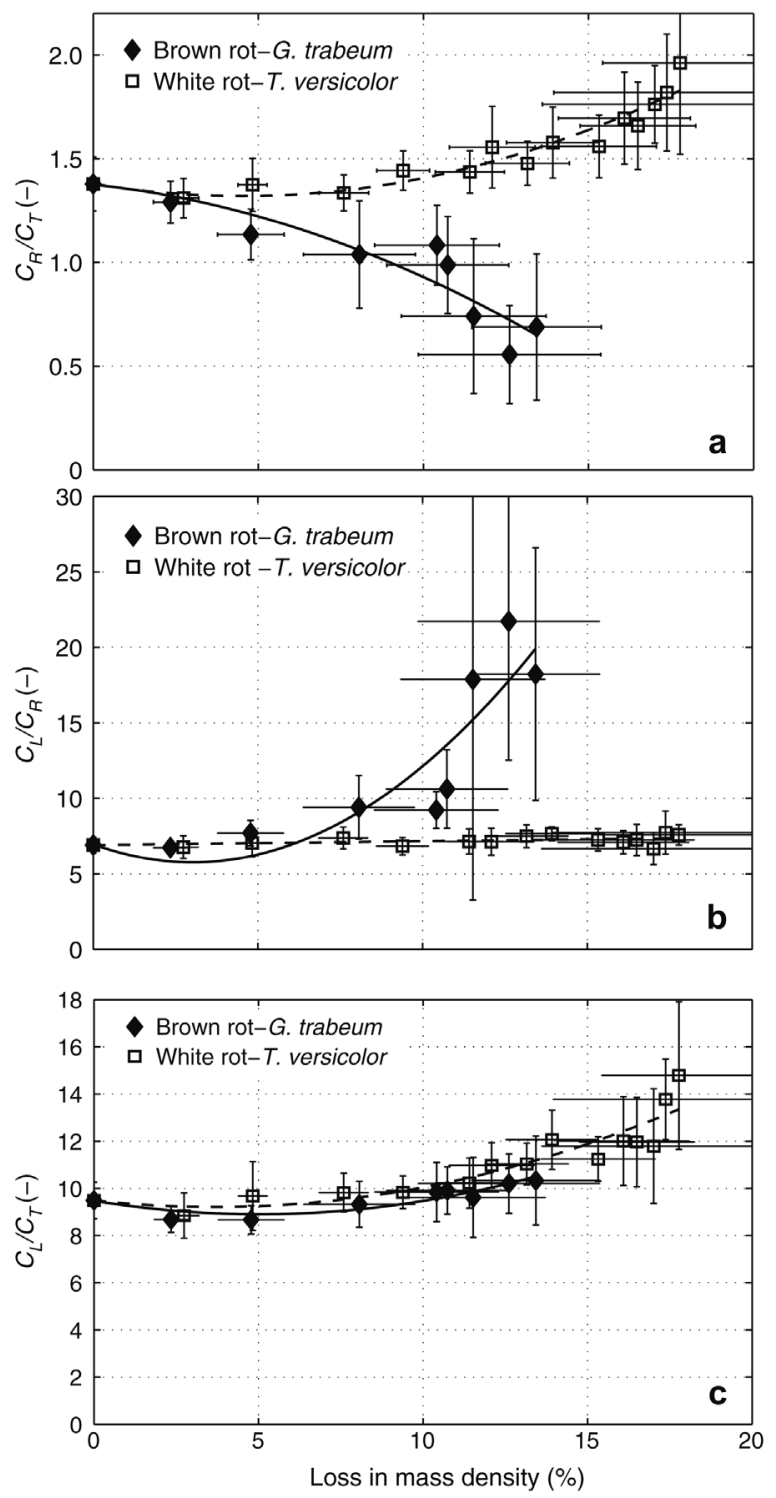

Figure 5 Change in anisotropy ratio of (a) radial to tangential stiffness, $C_{R} / C_{T}$, (b) longitudinal to radial stiffness $C_{L} / C_{R}$ and (c) longitudinal to tangential stiffness $C_{L} / C_{T}$ owing to degradation by G. trabeum and T. versicolor over corresponding loss in mass density. Error bars indicate corresponding standard deviations $(n=42$ for each degradation stage and fungus).

Here, also, transverse properties are much more affected by fungal degradation than longitudinal ones. In particular, stiffness in the tangential direction is most strongly weakened. Interestingly, this is opposite to the effects observed for G. trabeum.

To clarify the reasons for these reverse trends, the growth ring structure was investigated in more detail. In general, transverse stiffness properties of wood are strongly governed by the density variations from EW to LW and corresponding volume fractions. Recently, it was shown by X-ray microdensitometry that brown rot degradation (Coniophora putea$n a)$ of Scots pine affects the EW and LW regions differently (Macchioni and Palanti 2007). Considering the higher LW density by about a factor of 2.5 (Kollmann 1982), it is obvious that EW degradation more strongly affects radial properties than tangential ones. Based on the stiffness anisotropy ratios of $C_{R} / C_{T}$ for the two fungi (Figure 5a), it can be concluded that $G$. trabeum more strongly affects EW, while the opposite is true for T. versicolor. This result can be explained by the chemical composition of the wood matrix. LW contains more lignin than EW and T. versicolor (a white rot) can better metabolize lignin than the brown rot fungus G. trabeum.

These different effects on EW and LW are readily visible in cross-sections of $G$. trabeum-degraded samples, where color differences between EW and LW regions become more apparent with degradation time, while they are reduced in cross-sections of T. versicolor-degraded samples (Figure 1 in Bader et al. 2012).

When comparing changes in relative $E_{L}$ (Figure 4c) with alterations in the chemical composition (Figure 5 in Bader et al. 2012), the strong relation of $E_{L}$ to cellulose becomes evident. This is expressed by the same trends of the density related elastic modulus $E_{L} / \rho$ and cellulose over degradation time for G. trabeum degradation, as shown in Figure 6. Degradation of hemicelluloses and lignin, on the other hand, affect $E_{L}$ only to a minor degree. However, $C_{R}$ and $C_{T}$ are very sensitive to degradation of the latter polymer, hence these properties being more strongly reduced than $E_{L}$.
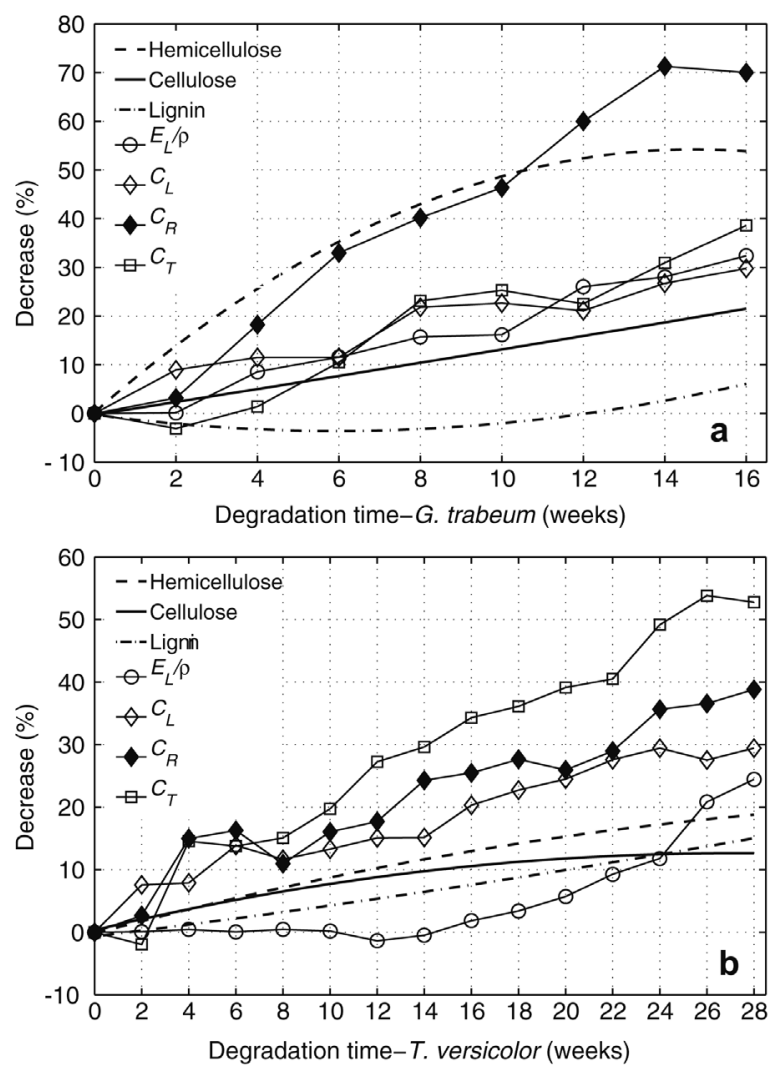

Figure 6 Change of weight fractions of chemical composition corrected with mass loss (hemicelluloses, lignin and cellulose), density related elastic modulus $\left(E_{L} / \rho\right)$ and stiffness properties $\left(C_{L}, C_{R}, C_{T}\right)$ for degradation by (a) G. trabeum and (b) T. versicolor. 
Fungal colonization starts at the surface and then diffuses into deeper layers (Schwarze 2007). This creates sizedependence of mechanical, chemical, and physical properties. It is most obvious in terms of ML, which was found to be elevated in the case of lowering mass of wood specimens (Bravery 1979).

As an alternative to the presented experimental approach, the gap between changes in chemical composition and corresponding mechanical properties can also be bridged by micromechanical modeling (Hofstetter et al. 2005, 2007; Bader et al. 2010, 2011), which has already been successfully applied to predict mechanical properties of clear wood. These models may even allow for verifying or falsifying hypotheses proposed for alterations in the microstructure, as the clear physical origin of the macroscopically-observed phenomenon is taken into account. Together with nanoindentation for assessing cell wall stiffness, such a model can enhance the current understanding of effects of fungal decay on the microstructure of wood. The suitability of this approach was recently verified for enzymatically-treated wood (Konnerth et al. 2010). As for fungal decay, the results of current research will be presented in the near future.

\section{Conclusions}

In the present study, physical, chemical (Bader et al. 2012), and mechanical properties of Scots pine sapwood have been investigated in an initial state of fungal degradation by G. trabeum and T. versicolor. It was demonstrated that transverse stiffness properties are much more affected by degradation than longitudinal properties owing to degradation of the matrix consisting of hemicelluloses and lignin. Longitudinal stiffness, however, is strongly related to cellulose microfibrils. In the case of G. trabeum degradation, radial stiffness is most strongly decreased by up to $70.0 \%$, and in case of $T$. versicolor degradation, tangential stiffness was most severly deteriorated up to $52.7 \%$, while corresponding longitudinal stiffnesses were only decreased by $29.8 \%$ and $29.4 \%$. Consequently, the anisotropy ratios measured by means of US testing are suitable indicators for quantification of the extent of degradation. The non-destructive US testing is relatively easy to apply and, thus, a suitable method for routine practice. The measured anisotropy ratios can also deliver insight into degradation and allow the drawing of conclusions on the activity of the fungus within the specimens. The degradation by G. trabeum and T. versicolor was shown to be different in EW and LW of Scots pine.

\section{Acknowledgements}

The authors gratefully acknowledge the financial support of the Austrian Research Promotion Agency (FFG, project number 815234/12971), The Research Council of Norway, WoodWisdomNet (www.woodwisdom.net), and the wood industry partnership 'Building with Wood' (embedded in CEI-Bois, the European Confederation of woodworking industries) through the projects 'MechWood' and 'WoodExter'. The research partners in these pro- jects are thanked for their cooperation and collaboration. The authors are very thankful to Christoph Wikete, Vienna University of Technology, for performing a considerable number of the mechanical tests and Monica Fongen and Eva Grondås, Norwegian Forest and Landscape Institute, for their chemical analyses.

\section{References}

Bader, T.K., Hofstetter, K., Hellmich, Ch., Eberhardsteiner, J. (2010) Poromechanical upscaling of wood strength: from lignin to spruce. Z. Angew. Math. Mech. 90:750-767.

Bader, T.K., Hofstetter, K., Alfredsen, G., Bollmus, S. (2012) Changes in microstructure and stiffness of Scots pine (Pinus sylvestris) sapwood degraded by Gloeophyllum trabeum and Trametes versicolor - Part I: Changes in chemical composition, density and equilibrium moisture content. Holzforschung 66:191-198.

Bader, T.K., Hofstetter, K., Hellmich, Ch., Eberhardsteiner, J. (2011) The poroelastic role of water in cell walls of the hierarchical composite "softwood". Acta Mech. 217:75-100.

Bravery, A.F. (1979) A miniaturized wood-block test for the rapid evaluation of wood preservative fungicides. In: Screening Techniques for Potential Wood Preservative Chemicals. Proceedings of a Special Seminar held in Association with the 10th Annual Meeting of the IRG, Peebles 1978. Swedish Wood Preservation Institute, Report No. 136. Stockholm.

Brischke, C., Welzbacher, C.R., Huckfeldt, T. (2008) Influence of fungal decay by different basidiomycetes on the structural integrity of Norway spruce wood. Holz Roh. Werkst. 66:433-438.

Bucur, V. (2006) Acoustics of Wood. 2nd edn. Springer Verlag, Berlin, Heidelberg, New York, 2006.

Côté, W.A. (1965) Cellular Ultrastructure of Woody Plants. Syracuse University Press, New York.

Curling, S., Clausen, C.A., Winandy, J.E. (2001) The effect of hemicellulose degradation on the mechanical properties of wood during brown rot decay. IRG/WP 01-20219.

Curling, S., Clausen, C.A., Winandy, J.E. (2002) Relationship between mechanical properties, weight loss, and chemical composition of wood during incipient brown-rot decay. Forest Prod. J. 52:34-39.

Eberhardsteiner, J. (2002) Mechanisches Verhalten von Fichtenholz: Experimentelle Bestimmung der biaxialen Festigkeitseigenschaften [Mechanical behavior of spruce wood: Experimental determination of biaxial strength properties]. Springer Verlag, Wien, New York (in German).

EN 113 (1996) Wood Preservatives Test - Method for Determining the Protective Effectiveness Against Wood Destroying Basidiomycetes - Determination of Toxic Values. Brussels, Belgium, European Committee for Standardization (CEN).

Fengel, D., Wegener, G. (1984) Wood - Chemistry, Ultrastructure, Reactions. 2nd edn. De Gruyter, Berlin, New York.

Gerhards, C.C. (1982) Effect of moisture content and temperature on the mechanical properties of wood: an analysis of immediate effects. Wood Fiber Sci. 14:4-36.

Hofstetter, K., Hellmich, Ch., Eberhardsteiner, J. (2005) Development and experimental validation of a continuum micromechanics model for the elasticity of wood. Eur. J. Mech. A Solids 24:1030-1053.

Hofstetter, K., Hellmich, Ch., Eberhardsteiner, J. (2007) Micromechanical modelling of solid-type and plate-type deformation patterns within softwood materials. A review and an improved approach. Holzforschung 61:343-351. 
Humar, M., Bŭcar, B., Vek, V., Pohleven, F. (2008) Changes of mechanical and chemical properties of wood after brown-rot decay and blue staining. Joint Meeting of COST Action IE0601 "Wood Science for Conservation of Cultural Heritage", and the European Society for Wood Mechanics. Braga, Portugal.

Itskov, M., Aksel, N. (2002) Elastic constants and their admissible values for incompressible and slightly compressible anisotropic materials. Acta Mech. 157:81-96.

Keunecke, D., Sonderegger, W., Pereteanu, K., Lüthi, T., Niemz, P. (2007) Determination of Young's and shear moduli of common yew and Norway spruce by means of ultrasonic waves. Wood Sci. Technol. 41:309-327.

Kollmann, F. (1982) Technologie des Holzes und der Holzwerkstoffe [Technology of Wood and Wood Products], 2nd edn, Vol. 1. Springer Verlag, Berlin, Heidelberg, New York (in German).

Kollmann, F., Côté, W. (1968) Principles of Wood Science and Technology, Vol. 1. Springer Verlag, Berlin, Heidelberg, New York.

Konnerth, J., Eiser, M., Jäger, A., Bader, T.K., Hofstetter, K., Follrich, J., Ters, T., Hansmann, C., Wimmer, R. (2010) Macro- and micromechanical properties of red oak wood (Quercus rubra L.) treated with hemicellulases. Holzforschung 64:447-453.

Korkut, S. (2008) The effects of heat treatment on some technological properties in Uludağ fir (Abies bornmuellerinana Mattf.) wood. Build. Env. 43:422-428.

Macchioni, N., Palanti, S. (2007) Measurements of fungal wood decay on Scots pine and beech by means of X-ray microdensitometry. Wood Sci. Technol. 41:417-426.

Przewloka, S.R., Crawford, D.M., Rammer, D.R., Buckner, D.L., Woodward, B.M., Li, G., Nicholas, D.D. (2008) Assessment of biodeterioration for the screening of new wood preservatives: calculation of stiffness loss in rapid decay testing. Holzforschung 62:270-276.

Ross, R.J., Pellerin, R.F. (1994) Nondestructive testing for assessing wood member in structures - A review. General Technical Report FPL-GTR-70. USDA Forest Serv., Forest Products Laboratory, Madison.

Salmén, L., Burgert, I. (2009) Cell wall features with regard to mechanical performance. A review. COST Action E35 2004-2008: wood machining - micromechanics and fracture. Holzforschung 63:121-129.

Schwarze, F.W.M.R. (2007) Wood decay under the microscope. Fung. Biol. Rev. 21:133-170.

Stevanic, J.S., Salmén, L. (2009) Orientation of the wood polymers in the cell wall of spruce wood fibres. Holzforschung 63:497503.

Wilcox, W.W. (1978) Review of literature on the effects of early stages of decay on wood strength. Wood Fiber 9:252-257.

Winandy, J.E., Clausen, C.A., Curling, S.F. (2000) Predicting the effects of decay on wood properties and modeling residual service-life. Proceedings of the 2nd Annual Conference on Durability and Disasters Mitigation in Wood-Frame Housing, November 6-8, 2000, Monona Terrace Convention Center, Madison, Wisconsin/sponsored by the PATH Consortium for Wood-Frame Housing in cooperation with the Forest Products Society. Forest Products Society, Madison, WI, pp. 261-263.

Received February 9, 2011. Accepted August 18, 2011. Previously published online September 13, 2011. 